ostium than normal persons, thus favoring the entrance of pollen and other substances. May we not explain the presence of hay fever in some and its absence in others by the varying size of the maxillary ostium? It is impossible in the limits of a letter to do more than to hint at the nature, locus morbi and treatment of the disease, but in a report now in prepa. ration the pathologic, anatomic and therapeutic facts of antral disease will be presented. The object of this communication is solely to endeavor to explain why pollantin and other socalled remedies fail to cure the distressing conditions, and to suggest that we have heretofore been directing our efforts to the wrong anatomic structures.

Jacob E. Schadle.

LeMars, Iowa, Aug. 17, 1906.

To the Editor:- I have been very much interested in the recital of the various physicians' experiences in the use of pollantin. This is the third season $I$ have used the serum in treating my hay-fever patient, and my experience with it has been very gratifying. I do not recall a single patient that has not been benefited by its use, and some hare told me that they have enjoyed comparative freedom from attacks by using the serum and powder fairly regularly throughout the season. I very much deprecate the container used for the medicine. It is a great nuisance for the physician to be obliged to remove all the advertising matter, etc., before dispensing the serum. Can not these people be induced to put the medicine out in some other form? It seems to me that those containers were made especially for display on the drug-store counter. Some time since I had some correspondence with Fritchie Brothers on this very point, and it was, to say the least, amusing to read their very lame explanations of the reasons for so doing. F. S. Clarke.

The Report of the Council on Medical Education.

To the Editor:-The recent report of the Council on Medical Education in The Journal A. M. A., June 16, 1906, page 1853, invites comment and suggestion. I am prompted to indulge in such comment because it seems to me that in this present time, full of great possibilities for advancement in medical ecilucation and practice, nothing will promote sure and rapid progress, and the avoidance of missteps, more certainly than a full and free discussion by all who are in any way related to, or interested in, the subject.

The decision of the Council to make its chief function that of co-ordinating the various forces at work among them, the medical schools and their associations, the literary colleges and medical examining boards, can not be too highly commended. It would have been a great mistake at this time to have attempted to force any arbitrary standards by drastic measures, such as the requirement that no physician, who failed to comply with certain standards, should be eligible for membership in the American Medical Association or in any of its constituent bodies. In this growing period of the Association the supreme effort should be to strengthen itself numerically by seeking the allegiance of every physician who is at all worthy of membership, and any action which would in. terfere with this movement would be unwise. In later years more radical measures and rigid standards may be indicated and may be possible of enforcement.

Most commendable atso is the decision of the Council to carry on the work inaugurated by $T_{H E}$ Journat some years ago of gathering information in reference to the medical schools, the medical practice acts and state board rulings, and of the results of the examinations for licensure in the several states, etc. It seems to me, however, that in reference to the statistics of the examinations for licensure the fact should be again emphasized that these statistics must not be interpreted too literally, nor can the results be accepted as furniching an accurate criterion of the relative merit of the several colleges. No one who is at all familiar with the character and the work of these schools can fail to discover that their relative rank, as they appear in the tables presented by the Council, bears little relation to their relative actual merit as teaching institutions. Some of the schools listed in the second group (showing from 10 to 20 per cent. of failures) or even the third group (over 20 per cent. of failures), are certainly not inferior to some of those which appear in Group I (having less than 10 per cent. of failures).

The reason for this is to be found in the wide discrepancy between the character of the examinations by the state boards -purely written tests as they are, almost without exceptionand the practical, objective methods of teaching in vogue in the better medical colleges. For a quarter of a century now, there has been a gradual and steadily growing departure from the purely didactic and "cram" methods of instruction toward the methods which develop in the student the power to see, to hear, to feel, to do and to think, by the actual exercise of his faculties in the laboratory, the practical course and the clinic. While this movement has been going on, the character of the examinations has changed not at all, and they are at present so far removed from the modern methods of education as to afford an entirely inadequate and unfair test of the student's accomplishments or of his ability to practice his profession. It is difficult to understand why the examining boards have been so slow to realize this fact when one remembers that really effective and rational methods of examination for licensure have been practiced in all foreign countries for many years. Possibly the explanation is partly to be found in the personnel of the examining boards, which have been so largely composed of men with no experience or training as teachers or examiners. Certainly, it seems to me, that so long as the state board examinations are conducted on lines so antiquated and so foreign to the modern methods of education in the high-grade medical schools, just so long will the results of these examinations be no fair criterion of the merits of these schools or of their graduates.

The most important items of the report of the Council are the recommendations: 1, For an ideal standard of requirements, and 2, for a fixed, uniform medical curriculum. The ideal standard proposed by the committee comprises six years of study between graduation from a four-year high_school and the reception of the degree of M.D. This arrangement proposes the addition of one year antecedent to one year subsequent to the present four-year medical curriculum, the antecedent year to be devoted to physics, chemistry, biology and German in preparation for the purely medical studies, while the closing year shall consist of practical work in a hospital or dispensary.

Few medical educators will dissent from the opinion that the time has come when a longer period than is now required must be given to preparation for the practice of medicine. The year of practical hospital training, already instituted by at least one American college, is of the utmost value, but not so indispensable as the provision for a more adequate preliminary training. Opinions will differ as to the sufficiency of one year of preparatory work beyond the high school, as requirement is already exacted in some colleges of two, three or four years, but all will welcome the addition of even one year of such work, provided, however, that it be done under such conditions and by such men as to insure its efficiency. And this is the point on which I wish to comment. To my mind the Council has made a grievous mistake in specifying that. this preparatory year may be done in the medical school, or in a literary or scientific college. The failure to insist that these branches of general learning (for such physics, chemistry, biology and German surely are), must be taken in a college or university, where alone, with very rare exceptions in this country, they are properly taught, results in making this recommendation of the Council a step backward rather than forward, because it will tend still further to defer that time, which I think we all realize should be the goal of our desires, when every medical graduate will be a broadly cultured, a college-bred man. What will be the actual working of this scheme to permit the medical school to add another year to its curriculum, and to exact another annual tuition fee from its students, may easily be foreseen by all who know the history of similar attempts of medical schools in former years to give instruction in non-medical branches. It is true that in Germany the gymnasium graduate enters the medical school with little or no scientific training-or did so until 
recently, but it is to be remembered that the situation in that country is wholly different from our own, for every medical school is an intimate and integral part of a university and the instruction in physics, chemistry and biology is in the hands of the university professors of these branches. The more strictly our own medical-purely professional-schools, devote themselves to the teaching of the purely medical branches, and the more completely they rely on institutions of general learning to do the preparatory work which belongs to them, the better will be the results secured. We may be sure that if the order for this preparatory year is promulgated by the examining boards as it is recommended by the Council, the very first institutions in the field with a blatant advertisement of their superior facilities for giving such instruction will be the most poorly equipped medical colleges, and those of the lowest standards. So far from operating to suppress the cheaper schools, the extinction of which is so greatly to be desirer, the effect will be to give them an additional hold on their students and to enable them to secure fees for another vear of relatively inexpensive instruction. It is very much to be hoped that before the action of the National Confederation of Examining Boards requiring this preparatory year goes into effect in 1910 , it will be so amended as to specify that this work must be taken in a literary or scientific college. It is hard to understand why there should be so much eagerness on the part of some to eliminate the literary and scientific schools from our scheme of medical education. The medical schools and the medical profession need their coöperation quite as much as they need our support, and no ideal scheme of medical education can be constructed in this country which fails to include them as an integral part of the system. It is true that there are poor and spurious colleges, as there are cheap medical schools, though the proportion is not so large, but these can be easily discovered and designated. The couneil should reckon as one of its most important functions such an investigation and classification of the literary and scientific colleges.

I had intended to comment on the so-called ideal curriculum which has been proposed by the council, as well as on other fixed curricula which have been laid down, among them that of the Michigan State Board. and of the Association of American Medical Colleges, but I have already trespassed too much on your space for one communication and must reserve this item for a later discussion.

JoHN M. DoDson.

\section{Wants to Arrest "Patent Medicine" Man.}

Albion, Mich., Aug. 20, 1906.

To the Editor:-I want information of one W. Thompson, "the oil man." He was arrested here for practicing medicine without a license, gave bail for appearance at hearing, and did not appear. He has since been in Ypsilanti, Mich., and Findlay, Ohio, and was last heard from in Windsor, Ont. He travels with four comedians, sells from a wagon, and is a very smooth talker, of dark complexion, straight black hair, rather below medium height, about 40 years of age. He sells a soap, a blood medicine, and "Egyption Oilio" (which is said to be colored gasoline), claims to represent a quarter-million dollar company, and has five diplomas. The sheriff is prepared to get him anywhere in the United States. If some physician who believes in protecting the public from swindling impostors will wire me on his appearance in any town we will be duly grateful and do the rest.

George C. HaFford.

A Yellow Peril.-Under this head J. W. Croskey, in the Medico-Chirurgical Journal, May 20, includes trachoma which he says is more prevalent in Japan than in any other country, although it is also common in India and Egypt. In all these countries its spread is favored by religious observances and superstitions such as ablutions with use of a common towel. The danger is shown by the fact that the proportion of trachoma cases in immigrants at eastern ports is less than one in 1,000 , while at western ports it rises to nearly one in 60 . Greater care in examination of immigrants and more stringent measures to prevent the spread of this disease are needed.

\section{Miscellany}

Effect of Alkalies and Other Drugs on the Efficiency of Pepsin.-While the therapeutic inefficiency of pepsin without the simultaneous presence of an acid, preferably hydrochloric acid, has been emphatically stated often enough so that it should be thoroughly understood, this ferment is still frequently prescribed in mixtures containing no acid and in combination with substances which destroy the enzyme, so as to defeat the purpose for which it was intended. Many neutral salts, alkaIoidal and other substances have been shown to have a retarding influence on the action of pepsin, while digestion with strong alkali destroys the enzyme altogether. J. F. Tocher has investigated the action of dilute alkalin solutions, as well as that of morphin and bismuth, substances which are often prescribed in mixtures with pepsin. He gives the following conclusions: 1. Solutions of sodium bicarbonate, sodium, potassium and ammonium hydrates when added to solutions of pepsin in the cold have an immediate inhibitory or destructive influence on pepsin, according to the concentration. In or. dinary concentrations the effect is to destroy the enzyme im. mediately. 2. Dilute solutions of caustic alkali immediately destroy the activity of dilute solutions of pepsin. One milli. meter (1 c.c.) of decinormal ammonia $\left(0.0017 \mathrm{gm} ., \mathrm{NH}_{3}\right)$ is sufficient to destroy the proteolytic power of $5 \mathrm{mgr}$. of pepsin in $5 \mathrm{~mm}$. ( 5 c.c.) of water. That is, a 0.1 per cent. solution of pepsin with an alkalinity equal to 0.017 per cent. has no proteolytic power whatever. On acidifying and digesting, the enzyme is found to be destroyed. Pepsin should, therefore, never be prescribed with alkalies. 3. Carbonate of bismuth precipitates pepsin from aqueous solutions; subnitrate of bismuth does not. 4. Compound mixtures containing solution of bismuth, morphin, carmin, etc., should contain no pepsin, since the activity of the enzyme is much retarded by the morphin and is destroyed proportionately to the amount of alkali pres('nt in solution.-Pharmaceutical Journal, July 28, 1906.

Ethyl Chlorid.-J. H. Chardecott, in the Clinical Journal for August, discusses the uses and abuses of this comparatively new anesthetic. It is interesting and somewhat instructive to note that the adoption of this anesthetic in England owes much of its progress to the advertisement of somnoform and that some of the abuses of the drug have been due to the misleading and unduly favorable reports sent out by these manufacturers. Chaldecott, after extensive use of ethyl chlorid, adheres in the main to the conclusions which he published in 1904: 1. It is the best anesthetic known for single-dose cases, viz., those in which anesthesia is inducel, the mask removed and the operation performed without any further administration. The statement still holds good for children, but in adults he prefers the nitrous oxid and ethyl chlorid mixture, which he regards as an ideal anesthetic in cases requiring an available anesthesia of from forty seconds to two minutes. 2. It is certainly worthy of an extensive trial in all minor operations. He does not see any advantage in ethyl chlorid after the first few minutes of anesthesia, it being more dificult to secure an even degree of narcosis than with ether or chloroform, and the after-effects of continued administration being practically identical with those of chloroform. 3. It is a safe and rapid means of inducing anesthesia as a preliminary to chloroform. This conclusion must be modified in the light of recent fatalities from the drug, and the ethyl chlorid ether sequence should be substituted for the gasether sequence only under circumstances which contraindicate the use of nitrous oxid. 4. Although its effects are transient, it is doubtless a powerful anesthetic and should be carefully administered and the patient properly prepared. The following objections to this anesthetic have been raised and are considered by Chaldecott: 1. Uncertainty of action. This has generally been due to the administration with too much air. 2. Rigidity. This has not been true in the author's experience. 3. After-effects. These have largely been due to imprudent use, and when the drug is properly administered they are very slight. 4. Danger to life. It must be admitted that although the proportion of fatal results is infinitesimal compared 